\title{
USING LONG-TERM FIELD EXPERIMENT DATA TO PREPARE A CROP SIMULATION MODEL FOR CLIMATE IMPACT STUDIES
}

\author{
MiCSKEI, GY. - FODOR, N. ${ }^{*}$ - MARTON, CS. - BÓNIS, P. - ÁRENDÁS, T. \\ Agricultural Institute, Centre for Agricultural Research, HAS \\ H-2462 Martonvásár, Brunszvik str. 2., Hungary \\ *Corresponding author: \\ Address: H-2462 Martonvásár, Brunszvik str. 2., Hungary \\ phone: +36208863720 \\ e-mail:fodor.nandor@agrar.mta.hu \\ (Received $29^{\text {th }}$ May 2015; accepted $16^{\text {th }}$ Feb 2016)
}

\begin{abstract}
This study presents the performance of the 4M crop model when simulating the effects of different fertilizer levels. Calculated biomass formation data were compared to observed data collected in a long-term field experiment launched in 1958 at Martonvásár, Hungary. After calibration, the model adequately simulated the differences between the effects of the different fertilization levels, as well as the long-term trends and averages of biomass productions. On the other hand, the model underestimated the inter-annual variability of the yield revealing a fundamental problem of crop modeling. A new formula was proposed to enable the model to simulate the increased leaf decay rate induced by heat and water stresses. The calibrated model was used to estimate the yields of 294 representatively selected Hungarian farms. After validation, the model was used for projecting the effects of fertilization in a future climate scenario. 4M predicted a considerable decrease of maize yields as well as yield safety for the future. The comparison of the observed and simulated data suggested two ways of model improvements which facilitate a more accurate projection of the impact of environmental stress factors.
\end{abstract}

Keywords: long-term experiment, maize, fertilization, crop modeling, climate change

\section{Introduction}

The Carpathian basin is an important area of crop production in Europe. Annually, around ten million tons of yields of different crops are produced here for 8 countries of the basin. The majority of the agricultural land in the basin (5.7 million hectares) is located in Hungary which ranks among the best in the world concerning the average yields of her main crops (maize, winter wheat and sunflower).

Since the 1960s in many countries in the world, including Hungary, agricultural production has gone through tremendous improvement. In Hungary the average yields of maize and winter wheat, were tripled in three decades compared to those of the 1950s. Together with introducing new, intensive cultivars and hybrids, one of the main factors behind this development was the enormous increase in fertilizer use. Compared to 1960 , by 1980 Hungarian arable land was given 10 times as much fertilizer. The same trend could be observed worldwide.

In the meantime, field experiments were launched to investigate the effect of different fertilization practices on yield characteristics (quantity, stability, etc.). In the early 1960s, a network of experimental stations (OMTK) was set up in Hungary to explore the potential (benefits and drawbacks) of fertilization in agricultural production (Kismányoky and Jolánkai, 2009). Locations were selected in a way to represent all major soil types and climatic zones of the country. Including the stations of OMTK, there are ongoing long-term experiments at more than 20 locations in Hungary with the oldest one launched in 1929. 
Although many times the initiators of the long-term experiments had only a quite limited idea what the collected data could be used for, during the past decades, many important applications have emerged from or been supported by these initiatives, such as fertilizer advisory systems (Fodor at al., 2011), soil carbon and nitrogen turnover models (Jenkinson, 1990), decision support tools (Gijsman et al., 2002), early warning systems of soil nutrient depletion (Korsaeth, 2012) and even new statistical methods (Fisher, 1921). Long-term experimentation is particularly important in understanding the changes that are occurring in the environment. Using the knowledge acquired in these living laboratories the effects of a certain manipulation may be separated from other variables, making it possible to manipulate almost any component and to be confident that one is able to predict the possible impacts (Southwood, 1994).

Process-based crop models are widely used in decision support systems or to assess impacts of climate change on agriculture at different spatial scales (Rosenzweig and Parry, 1994; Olesen and Bindi, 2002; Supit et al., 2010; Klein et al., 2012; Fodor et al., 2014). Since the projected changes of climate in the $21^{\text {st }}$ century show geographical patterns (IPCC, 2007) the impact studies provided region specific results (Semenov and Shewry, 2011; Ray et al., 2013; Ramirez-Cabral et al., 2016). For Europe, the case studies show an obscure picture for the future (Audsley et al., 2006; Supit et al., 2010). Despite the uncertainties climate change will most likely favour the winter crops and grass lands but introduces yield losses for spring crops in Southern and Central Europe.

According to Knox et al. (2012) and Fezzi et al. (2014) the potential major threats for agriculture include: 1) increased biotic stresses: pest, disease and weed problems; 2) increased abiotic stresses: heat, drought, water logging; 3) increased soil and wind erosion as well as nutrient loss (runoff and leaching); 4) higher GHG emission rates due to enhanced soil biological activity; 5) decreased water availability and quality. In addition to these, farmers will need to adapt to climate change mitigation policies, likely to involve increased costs of carbon emissions reflected in both their inputs (e.g. fertilisers) and outputs (e.g. higher transport costs). Alongside the threats, it seems that climate change will generate opportunities, as well (e.g. Peltonen-Sainio et al., 2009), including: 1) accelerated and more water-use-efficient crop growth; 2) lengthened growing and grazing season; 3) increased carbon sequestration; 4) expanded climatic suitability for agriculture; 5) introduction of new crops; 6) changes in crop rotation.

Long-term experiments provide excellent sources of data for developing, calibrating and validating crop simulation models (Jamieson et al., 1998; Eitzinger et al., 2004). Deterministic cropping system models could be successfully used in Education (e.g. with the aid of computers, virtual plant production competition could be organized among the students), in Research (e.g. the effects of yield-determining, -limiting and reducing factors could be disentangled and the results of observations could be extrapolated in time and space), in Practice (e.g. model results could be used in decision support systems as well as for supporting policy making). These impact models are the only tools (after careful calibration) for predicting the possible, agriculture-related effects of climate change. A comprehensive review of the usefulness of long-term experiments can be found in Science (Rasmussen et al., 1998).

In this study the $4 \mathrm{M}$ crop simulation model is presented and tested against measured data. Observed and simulated biomass formation data (LAI, yield, etc.) measured in a long-term fertilization experiment are compared. After calibration and validation the model is used for projecting the effects of fertilization in a future climate scenario. 


\section{Materials and Methods}

\section{Crop model}

The 4M crop simulation model (Fodor et al., 2002; Fodor and Pásztor, 2010) was used in the study. $4 \mathrm{M}$ is a daily-step, deterministic model. Its computations are determined by the numerical characteristics (defined by input parameters) of the atmosphere-soil-plant system. Besides the data that describe the physical, chemical and biological profile of the system, it is also necessary to set its initial, boundary and constraint conditions in the input file of the model. The parameters regulate the functions and equations of the model: the development and growth of plants and the heat, water and nutrient balance of the soil. The initial conditions are the measured system variables at the beginning of the simulation run such as the water and nutrient content of the soil. The boundary conditions are primarily the daily meteorological data such as global radiation, temperature and precipitation. The constraint conditions cover the numerical expressions of human activities such as data about planting, harvest, fertilization or irrigation. Besides plant development and growth, the model calculates the water, heat and nitrogen flow as well as the nitrogen transformation processes of the soil: e.g. the amount of nitrate that percolates down under the root zone and the amount of the $\mathrm{NO}_{\mathrm{x}}$ gases released from the soil due to denitrification (Fig 1). More detailed description of the model can be found in Fodor et al. (2012) and Sándor and Fodor (2012).

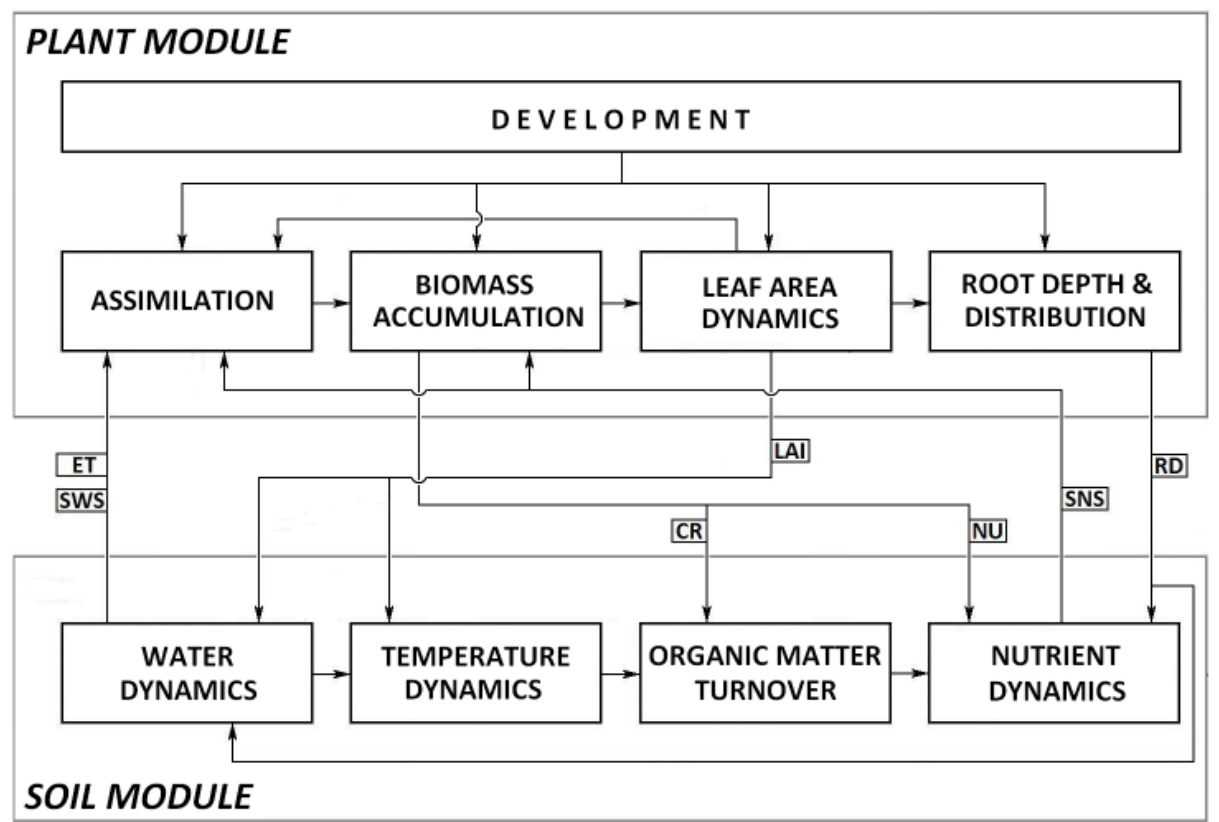

Figure 1. Flow chart of the $4 M$ crop simulation model. Indicated system variables: $E T-$ evapotranspiration, $S W S$ - soil water status, $L A I$ - leaf area index, CR - crop residue, $N U$ nutrient uptake, SNS - soil nutrient status, RD - rooting depth.

4M is basically a CERES [12] clone, rewritten in JAVA. Since its first release in 2002, three major developments have been made to the original version: 1) a new module was added to calculate the growth and the maintenance respiration as well as the $\mathrm{CO}_{2}$ emission of plants (Fodor et al., 2014), 2) a phosphorus module was added to 
calculate soil P dynamics and plant P uptake (Máthé-Gáspár and Fodor, 2014), 3) a new function was added to account for the heat and water stress induced canopy decay. In addition to these developments, in $4 \mathrm{M}$, practically every model parameter is accessible by the user through a graphical user interface.

\section{Model improvement}

Owing to the continuous development efforts in the past decades crop models are adequately able to predict the long-term trends and averages of biomass production. Despite this fact, at their present stage, crop models are unable to handle the effects of environmental stress factors (heat waves, droughts, etc.) adequately. The year 2007 provided an excellent possibility to improve the leaf senescence module of the model. The CERES model, and consequently the 4M model, does not take the effect of extreme air temperature and water shortage into account when calculating the daily rate of leaf senescence. Due to this fact, these models tend to overestimate the maize leaf area in the post-flowering period. $4 \mathrm{M}$ calculates the age of the leaf in thermal time measured in degree days $\left({ }^{\circ} \mathrm{Cd}\right)$. When the leaf age exceeds the lifespan of the leaf (input parameter) the leaf dies. Based on observations a simple equation is proposed to enable the model to simulate the increased leaf decay rate $(\mathrm{LDR})$ induced by heat $\left(\mathrm{H}_{\mathrm{str}}\right)$ and water $\left(\mathrm{W}_{\mathrm{str}}\right)$ stresses (Eq. 1). These two factors are simply added to the original formula.

$$
\mathrm{LDR}=\operatorname{DTT} \cdot\left(1+\mathrm{a} \cdot \mathrm{H}_{\mathrm{str}}+\mathrm{b} \cdot \mathrm{W}_{\mathrm{str}}\right)
$$

Where DTT denotes the daily thermal time $\left({ }^{\circ} \mathrm{Cd}\right)$ which is the difference between the daily average temperature and the base temperature with the condition of DTT $\geq 0$. The value of the $a$ and $b$ parameters is to be determined during the model calibration. Both stress factors range between zero and one. $\mathrm{H}_{\text {str }}$ is zero if the daily maximum temperature $\left(\mathrm{T}_{\max }\right)$ is below $35^{\circ} \mathrm{C}$ and equals one if $\mathrm{T}_{\max }$ reaches or exceeds $40{ }^{\circ} \mathrm{C}$. Between the two limits a linear increase is postulated. $\mathrm{W}_{\text {str }}$ is zero if the soil is wet enough to enable the plants to take up sufficient amount of water for the daily transpiration. Supposing a linear trend, $\mathrm{W}_{\text {str }}$ increases to one as the soil water content drops to the wilting point in the root zone.

\section{Long-term experiment}

The maize (Zea mays) monoculture experiment was launched in 1958 with seven fertilizer treatments. In this study, only the treatments with inorganic fertilizers have been investigated: control, $\mathrm{N}_{1} \mathrm{P}_{1} \mathrm{~K}_{1}, \mathrm{~N}_{2} \mathrm{P}_{2} \mathrm{~K}_{2}$. Each treatment was represented in seven replicates using $8 \times 10 \mathrm{~m}=80 \mathrm{~m}^{2}$ size parcels in a Latin square arrangement. The $\mathrm{P}$ (superphosphate, $\mathrm{Ca}\left(\mathrm{H}_{2} \mathrm{PO}_{4}\right)_{2}$ ) and $\mathrm{K}$ (potassium chloride, $\mathrm{KCl}$ ) fertilizers were applied in every fourth year (started in 1958), before the autumn tillage. $\mathrm{N}$ fertilizer (ammonium nitrate, $\mathrm{NH}_{4} \mathrm{NO}_{3}$ ) was applied every spring before making the seedbed. Autumn soil disinfections and pre-flowering pesticide spraying were applied against pests (e.g. maize bug (Diabrotica virgifera virgifera)) to minimize their damage. Pre- and post-emergent herbicides were applied annually to keep the parcels clean from weeds. 


\section{Meteorological data}

A database of the Hungarian Meteorological Service for the 1961-2010 period was used in the study: including daily global radiation, maximum and minimum temperature and precipitation, covering the area of Hungary with an $10 \times 10 \mathrm{~km}$ resolution grid. The MISH interpolation technique (Szentimrey et al. 2011) was used for producing the grid of meteorological data from the local observations. The country is covered by 466 rectangles considered meteorologically homogenous. 50-year long dataseries of the grid cell in which the long-term experiment is located (Martonvásár, long: 49 $19^{\prime} 28^{\prime}$, lat: $18^{\circ} 47^{\prime} 26^{\prime \prime}$ ) were used as model inputs (Fig. 2).
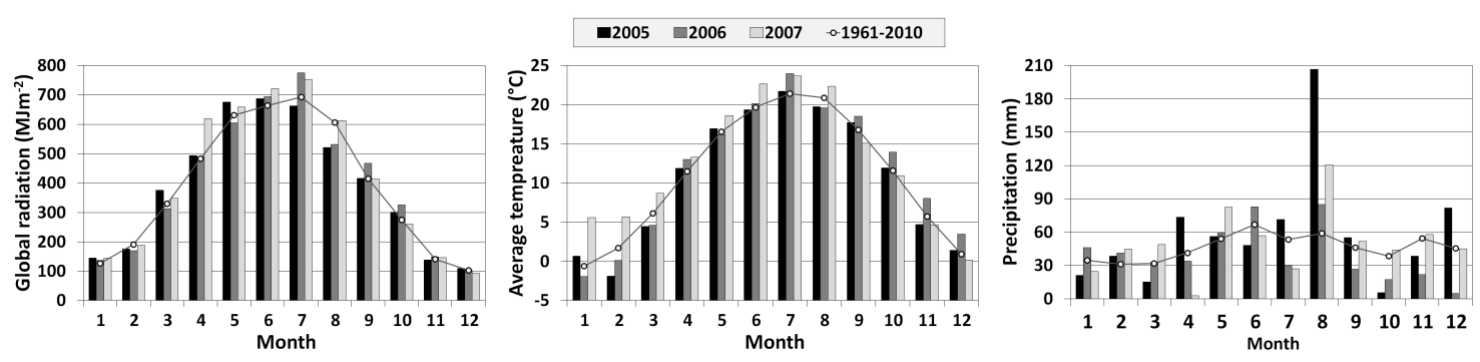

Figure 2. Characteristics of the meteorological data series used in the study.

\section{Soil data}

The soil of the experiment belongs to the chernozem FAO soil unit as well as to the medium textural class (sand fraction: $51.4 \%$, silt fraction: $34.0 \%$, clay fraction: $14.6 \%$ ) with a deep $(>40 \mathrm{~cm})$ A horizon. Characteristic values of the soil water retention curve were determined with an Eijkelkamp sand/kaolin box as well as with a pressure membrane apparatus. For this measurement, five $100 \mathrm{~cm}^{3}$ undisturbed core samples were collected from the topsoil $(0-20 \mathrm{~cm}$ depth). According to the measurements the saturated water content, the field capacity and the wilting point water content of the soil is $0.49,0.31$ and $0.09 \mathrm{~cm}^{3} \mathrm{~cm}^{-3}$, respectively. Bulk density was determined using the same core samples resulting in a $1.47 \mathrm{gcm}^{3}$ average value. Saturated hydraulic conductivity of the soil was measured in situ with a Decagon mini disc infiltrometer. The measurements were carried out in five replicates providing a $9 \mathrm{cmd}^{-1}$ average value. Other important soil characteristics are summarized in Table 1. Soil humus as well as ammonium lactate (AL) soluble $\mathrm{P}$ and $\mathrm{K}$ contents were determined according to the method of Tyurin (1937) and Egner et al. (1960), respectively. The AL method is a quite widespread soil analysis method used in more than 10 countries in Europe including the Netherlands, Portugal, and Sweden. At the beginning of the long-term experiment the average soil humus, $\mathrm{AL}-\mathrm{P}_{2} \mathrm{O}_{5}$ and $\mathrm{AL}-\mathrm{K}_{2} \mathrm{O}$ content was $2.9 \%, 45 \mathrm{mgkg}^{-}$ ${ }^{1}$ and $240 \mathrm{mgkg}^{-1}$, respectively.

Table 1. Soil chemical characteristics of the field experiment, 30 years after the start, in 1990.

\begin{tabular}{lllll}
\hline Treatments & $\begin{array}{l}\text { Humus content } \\
(\%)\end{array}$ & $\mathrm{pH}_{\mathrm{KCl}}$ & $\begin{array}{l}\mathrm{AL}^{\mathrm{P}} \mathrm{P}_{2} \mathrm{O}_{5} \\
\left(\mathrm{mgkg}^{-1}\right)\end{array}$ & $\begin{array}{l}\mathrm{AL}-\mathrm{K}_{2} \mathrm{O} \\
\left(\mathrm{mgkg}^{-1}\right)\end{array}$ \\
\hline Control & 2.82 & 6.08 & 32.4 & 218 \\
$\mathrm{~N}_{1} \mathrm{P}_{1} \mathrm{~K}_{1}$ & 2.91 & 5.85 & 69.0 & 251 \\
$\mathrm{~N}_{2} \mathrm{P}_{2} \mathrm{~K}_{2}$ & 2.92 & 5.42 & 125.3 & 380 \\
\hline
\end{tabular}




\section{Agromanagement data}

Soil cultivation, planting, fertilization, spraying and harvest dates, as well as the amount of the applied materials (seeds, fertilizers, etc.) have been carefully recorded since the beginning of the long-term experiment. The control, the $\mathrm{N}_{1} \mathrm{P}_{1} \mathrm{~K}_{1}$ and the $\mathrm{N}_{2} \mathrm{P}_{2} \mathrm{~K}_{2}$ treatments received zero, 66/38/75 and 132/76/150 N/ $\mathrm{P}_{2} \mathrm{O}_{5} / \mathrm{K}_{2} \mathrm{O} \mathrm{kgha}^{-1} \mathrm{y}^{-1}$ active ingredients, respectively. In the first period (1959-1974) of the experiment late varieties (FAO 500-600) were sown, while in the second period (1975-1990) early hybrids (FAO 300-400) were preferred. It has to be emphasized, that since 1991, the NORMA hybrid (FAO 380) has been used. Sowing was scheduled to the second half of April (depending on the weather and soil conditions) every year with 7 plants per $\mathrm{m}^{2}$ density and $70 \mathrm{~cm}$ row distance. After harvest, the crop residue was always incorporated into the soil with the autumn tillage. The changes of cultivars during the experiment were taken into account in the simulations in a simple way. For the cultivars of the late FAO group longer phenological stages were set in the input files. Since the newer cultivars do not have a significantly higher radiation use efficiency (RUE), thus a single, fixed RUE value was used throughout the 50 year-long simulated period.

\section{Data used for model calibration (2005-2007)}

The observed meteorological, soil and agromanagement data were used as model inputs. The approximate values of the plant specific parameters (phenological characteristics, maximum root depth, light use efficiency, specific leaf area, specific $\mathrm{N}$ content, etc.) were determined based on the relevant scientific literature (Hodges, 1990), (Stockle and Nelson, 1996). Then, the parameters were fine-tuned using an inverse modeling technique (Soetaert and Petzoldt, 2010) so that the observed and simulated biomass formation dynamics would be as similar as possible. For this comparison, three plants were cut out from the replicates of all treatments (control, $\mathrm{N}_{1} \mathrm{P}_{1} \mathrm{~K}_{1}$ and $\mathrm{N}_{2} \mathrm{P}_{2} \mathrm{~K}_{2}$ ) every two weeks starting at the 4-leaf stage and finishing at physiological maturity. The parcels were sampled ten times during each vegetation period. The sample plants were cut into pieces and the parts were separated into 'stem', 'leaf' and 'yield' groups. The area of the leaves was measured with a LI-3100A leaf area meter. Stem, leaf and yield dry weights were measured after 48 hours of drying at $105^{\circ} \mathrm{C}$ temperature. In addition to these, the occurrence dates of the main phenological stages were recorded. Specific leaf area (SLA) was determined by using the observed leaf area and the corresponding leaf dry weight data. The calculated SLA value $\left(15.4 \mathrm{~m}^{2} \mathrm{~kg}^{-1}\right)$ was provided for the model as an input. Base temperature and the maximum root depth were set to $8{ }^{\circ} \mathrm{C}$ and $1.7 \mathrm{~m}$, respectively. The following parameters were fine-tuned (determined with inverse modeling) by minimizing the absolute error between the observed and the simulated flowering and maturity dates as well as the LAI, biomass and yield data for the year 2005, 2006 and 2007:

- Cumulative thermal time from emergence to flowering $\left({ }^{\circ} \mathrm{Cd}\right)$

- Cumulative thermal time from flowering to physiological maturity $\left({ }^{\circ} \mathrm{Cd}\right)$

- Radiation use efficiency $\left(\mathrm{kgMJ}^{-1}\right)$

- Mass partition among root/stem/leaf in the early growth stage (\%)

- Mass partition among root/stem/leaf after the early growth stage till flowering (\%)

- Lifespan of leaves $\left({ }^{\circ} \mathrm{Cd}\right)$

- Parameters ( $\mathrm{a}$ and $\mathrm{b}$ ) of the leaf senescence equation (Eq. 1) 
The first two parameters govern the phenological development of the simulated plants, while the rest of the parameters determine the plant growth: biomass formation, allocation and senescence. Within the long-term experiment dataset we had the details on plant growth only for these three years (2005-2007). Minolta SPAD 502 portable chlorophyll-meter was also used to determine leaf chlorophyll content in the grain filling period according to Schepers et al. (1992). This data was not used for calibrating the model, just for interpreting the calibration results. The model performance was evaluated by using the mean relative error and the Nash-Sutcliffe model efficiency coefficient, ENS (Nash and Sutcliffe, 1970).

$$
E N S=1-\frac{\sum_{n=1}^{N}\left(V_{n}^{o}-V_{n}^{c}\right)^{2}}{\sum_{n=1}^{N}\left(V_{n}^{o}-M^{o}\right)^{2}}
$$

where $\mathrm{M}^{\mathrm{o}}$ is the mean of observed values, $\mathrm{V}^{\mathrm{o}}$ and $\mathrm{V}^{\mathrm{c}}$ are the observed and calculated values, respectively, and $\mathrm{N}$ is the number of observations.

ENS can range from $-\infty$ to 1 . ENS $=1$ corresponds to a perfect model performance. An efficiency less than zero (ENS < 0) occurs when the observed mean is a better predictor than the model meaning that the model is practically useless. The closer the efficiency coefficient is to 1 , the more accurate the model is.

\section{Data used for model validation (1961-2010)}

After calibrating the model, it was validated in a two-way process. First, the model performance was assessed with the help of the 50-year long data series of the long-term experiment. Though the calibration and validation datasets were not entirely independent, for the sake of continuity, data from the 2005-2007 period was included in the investigated 50-year long period. Since this 3-year long period gives only $6 \%$ of the 1961-2010 period, it was assumed that this 'malpractice' would not distort the validation results. The observed and simulated cumulated yields were compared for the control, the $\mathrm{N}_{1} \mathrm{P}_{1} \mathrm{~K}_{1}$ and the $\mathrm{N}_{2} \mathrm{P}_{2} \mathrm{~K}_{2}$ treatments using simple graphs, while for the annual yields simple statistical indicators (e.g. RMSE and t-value) were used. Paired t-tests were carried out with $\alpha=0.05$ confidence level. Second, the model performance was evaluated using real farm data. Data of 294 representatively selected Hungarian agricultural enterprises (regarding their spatial distribution within the country) were used from the period of 2001-2010. The available data included the geographical location of the parcels with maize, time of the agro-technical operations, amount of the applied fertilizers and final yields. The required soil input parameters were retrieved from the $0.1 \times 0.1 \mathrm{~km}$ resolution soil database of Hungary (Pásztor et al., 2014). Daily meteorological inputs were retrieved from $10 \times 10 \mathrm{~km}$ resolution CarpatClim database (Spinoni et al., 2014). The observed and simulated yields were compared using graphs and indicators similar to those of the first validation step.

\section{Impact projection of fertilizer practices using a future climate scenario}

A climate scenario was constructed based on the outputs of the ARPEGE-CLIMATE global circulation model (Déqué et al., 1998), which was then dynamically downscaled for Hungary with the ALADIN-Climate V4.5 regional climate model (RCM) (Wang et 
al., 2011). The IPCC SRES A1B scenario (Nakicenovic and Swart, 2000) was used in the ALADIN simulations. RCMs, similarly to models used in numerical weather prediction, create realistic daily meteorological data taking into account the future changes (defined by the IPCC SRES A1B scenario in our case) in the chemical composition of the atmosphere and the consequent alteration of the radiation balance of the atmosphere. Thus, no additional statistical/synthetic method (e.g. weather generator) is required for producing daily time-step meteorological data. The $10 \mathrm{~km}$ horizontal resolution outputs of the RCM (daily maximum/minimum temperature and precipitation data for the 1951-2110 period) were validated using the interpolated gridded dataset of observed data over Hungary for the 1961-1990 reference period (CECILIA 2013). The average prospective changes of the monthly climatic variables were estimated by comparing the data of the 1961-1990 (measured) and the 2061-2090 (climate model output) periods (Fig 3).

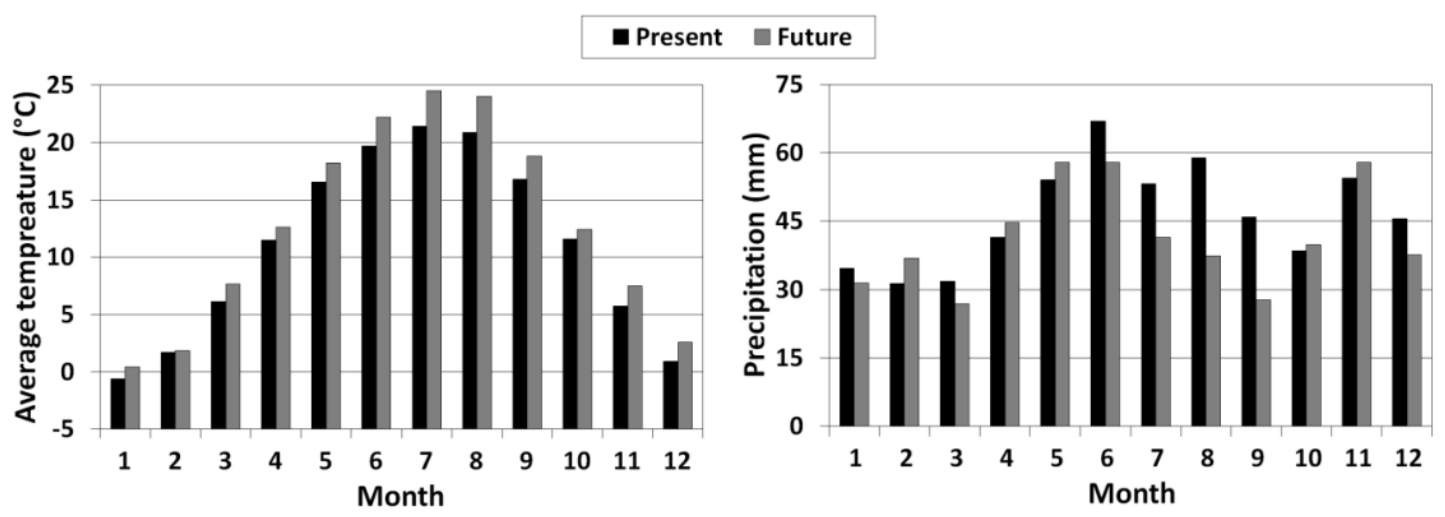

Figure 3. Climatic characteristics of weather data used in the study. Present: 1961-1990, Future: 2061-2090.

Model simulations were carried out for the present (1961-2010) and for the future (2061-2110) using measured and projected meteorological data, respectively. It was postulated that the atmospheric $\mathrm{CO}_{2}$ concentration was 350 and $700 \mathrm{ppm}$ in the present and future period, respectively (IPCC 2014).

\section{Results and Discussion}

Observed data clearly show that small leaves (shooting out in the early generative stage) have considerably larger specific leaf area than that of the large leaves (Fig. 4.). This characteristic difference was taken into account during the simulations by setting different SLA values in the model for the early and the late growth stages.

\section{Model calibration}

Plant parameter values obtained during the model calibration are summarized in Table 2. For the sake of clarity only the control and the $\mathrm{N}_{2} \mathrm{P}_{2} \mathrm{~K}_{2}$ treatments are presented in the graphs that summarize the observed and simulated LAI, biomass and yield data for the calibration period (2005-2007). 


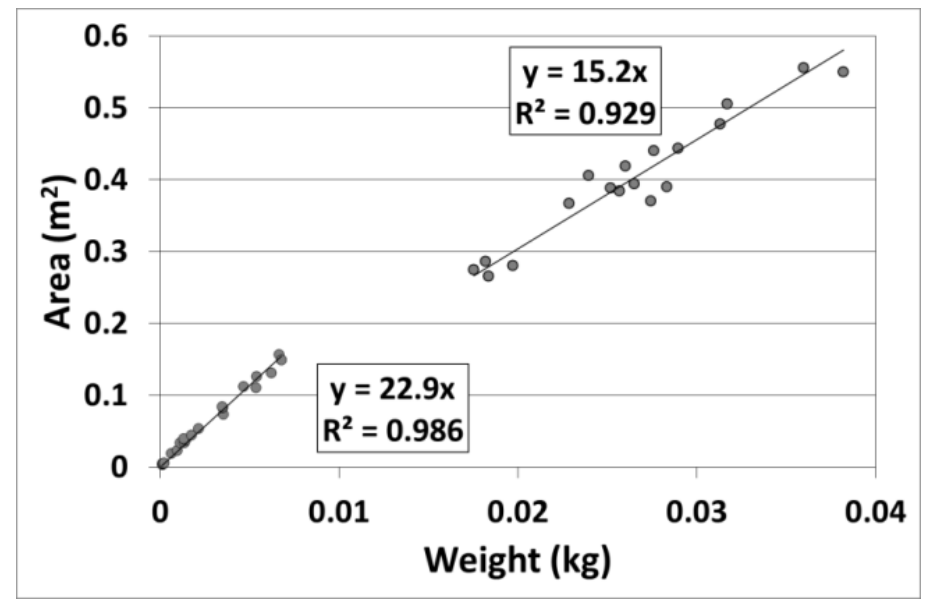

Figure 4. Leaf area vs. leaf weight in the year 2005, 2006 and 2007. The slope of the fitted line provides the specific leaf area parameter for the crop model.

Table 2. Plant parameters of the early hybrids (FAO 300-400) obtained during the calibration of the model.

\begin{tabular}{|c|c|}
\hline Parameter & Value \\
\hline Cumulative thermal time from emergence to flowering $\left({ }^{\circ} \mathrm{Cd}\right)$ & 800 \\
\hline $\begin{array}{l}\text { Cumulative thermal time from flowering to physiological maturity } \\
\left({ }^{\circ} \mathrm{Cd}\right)\end{array}$ & 1000 \\
\hline Radiation use efficiency $\left(\mathrm{kgMJ}^{-1}\right)$ & 0.003 \\
\hline Mass partition among root/stem/leaf in the early generative stage $(\%)$ & $30 / 5 / 65$ \\
\hline Mass partition among root/stem/leaf in the late generative stage $(\%)$ & $25 / 50 / 25$ \\
\hline Lifespan of leaves $\left({ }^{\circ} \mathrm{Cd}\right)$ & 1100 \\
\hline Leaf senescence parameters (Eq. 1.)) & $1.0 / 0.6$ \\
\hline
\end{tabular}

The model tends to underestimate the leaf area, especially for the control treatment where the plants were growing in a nitrogen limited environment as this treatment received zero $\mathrm{N}$ fertilizer in the past 50 years. Despite of this, the model gave fairly good estimations for the biomass and the yield even for 2007, when the model considerably underestimated the LAI for all of the treatments (Fig. 5.). This apparent contradiction could be resolved with the following argumentation. In nitrogen limited environments maize plants tend to allocate proportionally more mass to the leaves than in an environment with optimal nutrient supply. According to the observations, in the period of the most intensive growth period (50-70 days after sowing), the leaf growth rate accounted for 43.4 and $34.8 \%$ of the biomass growth rate for the control and the $\mathrm{N}_{2} \mathrm{P}_{2} \mathrm{~K}_{2}$ treatments, respectively. On the other hand, leaves of the plants in the control treatment had significantly lower chlorophyll content (smaller corresponding radiation use efficiency) according to the observations (Fig. 6.). Since these two reversely acting phenomenon are not taken into account in the model, the simulated plants with smaller leaf area, but with higher radiation use efficiency might be able to produce (virtually) 
similar amounts of biomass to that of the real ones. That is to say that, though the model considerably underestimated the leaf area expansion of the plants in the control treatment, the calculated biomass production was similar to that of the real one since the photosynthetic activity in the model does not decrease with the lower nitrogen availability, unlike in real plants.
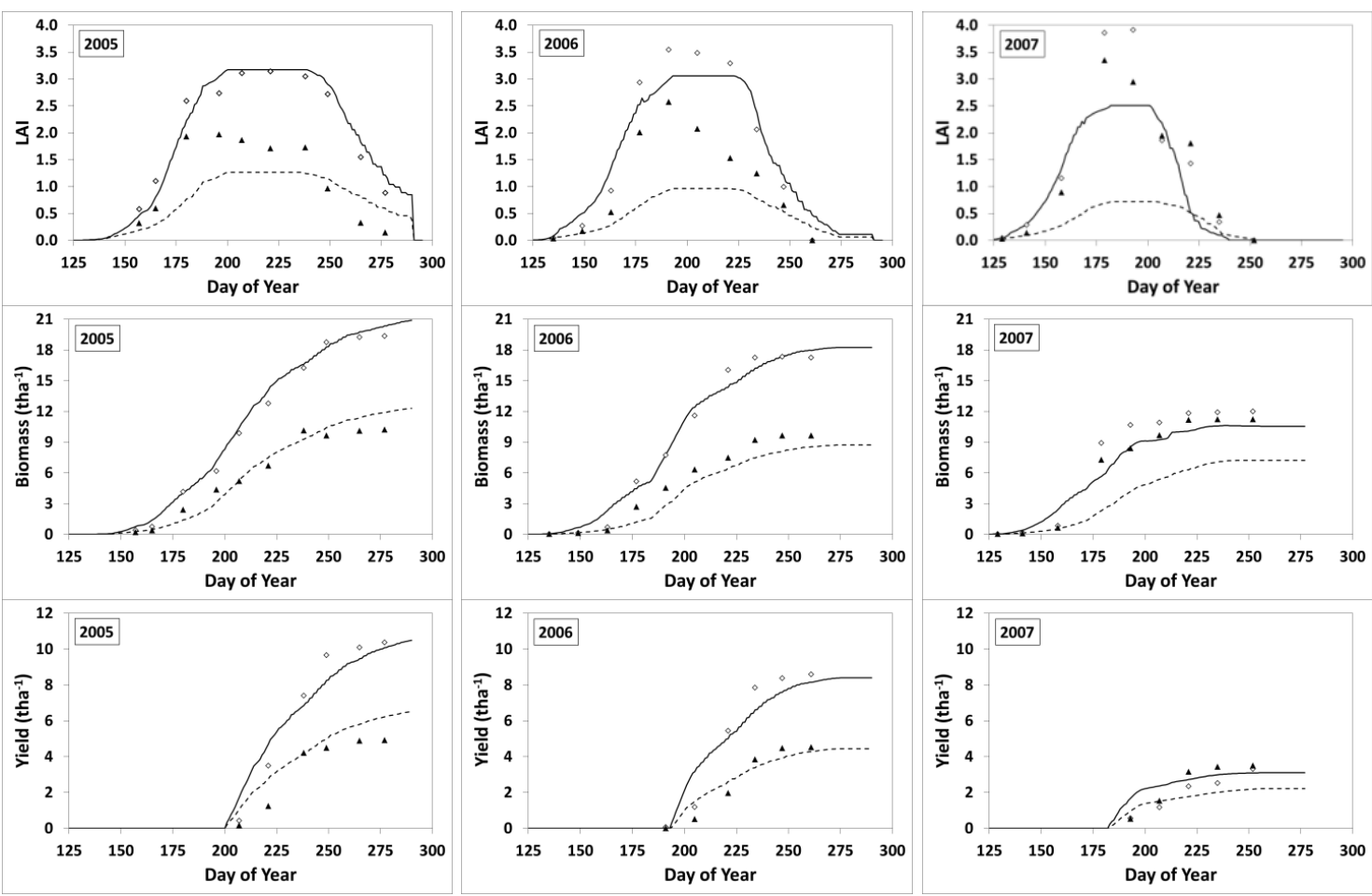

Figure 5. Observed (dots) and simulated (lines) data for the 2005-2007 period. Diamonds and continuous lines denote the $N 2 P 2 K 2$ treatment while triangles and dashed lines represent the control treatment. Plants were sampled 9-10 times in each vegetation period and dots present the average of the measured values for each sampling dates.

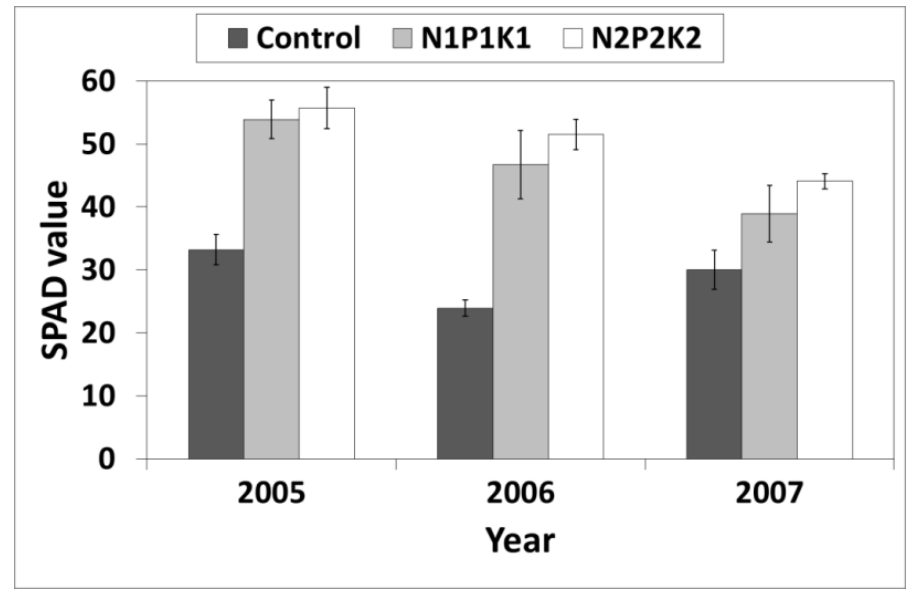

Figure 6. Effect of fertilization level on the leaf chlorophyll content. SPAD denotes the relative chlorophyll content index. Bars denote the standard deviation of the measurement replicates.

The annual averages were significantly different according to the $t$-tests $(\alpha=0.05)$ for all treatments and for all pair of years. The only exception was the 2005-2007 comparison for the control treatment. 
The model was able to simulate the differences between the years, as well as the effects of the different fertilization levels. $4 \mathrm{M}$ gave better biomass and yield predictions for the higher N-level treatments: The mean relative errors of the biomass (yield) estimations were 22 (22), 8 (9) and 6 (4) \% for the control, $\mathrm{N}_{1} \mathrm{P}_{1} \mathrm{~K}_{1}$ and $\mathrm{N}_{2} \mathrm{P}_{2} \mathrm{~K}_{2}$ treatments, respectively. The Nash-Sutcliffe model efficiency coefficients were summarized in Table 3. Except for the leaf area index in 2007 the NSE values were positive. Additionally, NSE values were close to 1 for biomass and yield in most of the cases meaning that the model is able to provide reliable estimates of these parameters. In addition, the model provided better estimations for years with more or with more evenly distributed precipitation (2006 vs 2007 in Fig. 2.). The mean relative errors of the biomass (yield) estimations were 9 (11), 7 (5) and 20 (23) \% for the year 2005, 2006 and 2007, respectively.

In 2007 there was practically zero precipitation in April and only $35 \mathrm{~mm}$ of rain (mainly from sporadic light showers, $>5 \mathrm{mmd}^{-1}$ rain was recorded only on two days) was registered between the $10^{\text {th }}$ of June and the $10^{\text {th }}$ of August. Despite of this the highest LAI was recorded in this year. Leaf area climaxed in the first decade of July that was followed by a week-long heat wave with maximum temperatures above $35^{\circ} \mathrm{C}$. The extreme temperature and the water deficit stress caused rapid leaf senescence when the leaf area fell by one-half within two weeks. The model, with the enhanced leaf senescence method, simulated fairly well the declining section of the leaf area curves (Fig. 5.) even for the extreme weather conditions in 2007. Since the model failed to adequately calculate the leaf area maximum for this year, the LAI values were seriously underestimated for the rest of the vegetation period, even though the tangents of the observed and simulated leaf area declination were similar (Fig. 5.). Obviously, the proposed leaf senescence method is unable to simulate the rate of the canopy decay for the control treatment where most likely the nitrogen deficit stress increased the senescence rate as the observed data suggest (Fig. 5.).

Table 3. Nash-Sutcliffe model efficiency coefficients (NSE) obtained during the model calibration.

\begin{tabular}{lll}
\hline Parameter & Year & $\mathrm{NSE}\left(\right.$ control $/ \mathrm{N}_{2} \mathrm{P}_{2} \mathrm{~K}_{2}$ treatment $)$ \\
\hline LAI & & $0.651 / 0.978$ \\
Biomass & 2005 & $0.939 / 0.990$ \\
Yield & & $0.911 / 0.983$ \\
\hline LAI & & $0.190 / 0.932$ \\
Biomass & 2006 & $0.904 / 0.983$ \\
Yield & & $0.924 / 0.979$ \\
\hline LAI & & $-0.201 / 0.733$ \\
Biomass & 2007 & $0.415 / 0.885$ \\
Yield & & $0.909 / 0.967$ \\
\hline
\end{tabular}




\section{Model validation}

The root mean squared error (RMSE), the mean absolute error (MAE) and the mean relative error (MRE) of the yield simulations were the following for the three investigated treatments for the 1961-2010 period. Control: RMSE $=1.19$ tha $^{-1}, \mathrm{MAE}=$ 0.94 tha $^{-1}, \mathrm{MRE}=29 \% ; \mathrm{N}_{1} \mathrm{P}_{1} \mathrm{~K}_{1}: \mathrm{RMSE}=1.35 \mathrm{tha}^{-1}, \mathrm{MAE}=1.13 \mathrm{tha}^{-1}, \mathrm{MRE}=23 \%$; $\mathrm{N}_{2} \mathrm{P}_{2} \mathrm{~K}_{2}$ : RMSE $=1.43$ tha $^{-1}, \mathrm{MAE}=1.23 \mathrm{tha}^{-1}, \mathrm{MRE}=20 \%$. The expected value of the observed and the simulated yields were 3.6, 5.8, 6.3 tha ${ }^{-1}$ and 3.3, 5.6, 6.0 tha $a^{-1}$ for the control, $\mathrm{N}_{1} \mathrm{P}_{1} \mathrm{~K}_{1}$ and $\mathrm{N}_{2} \mathrm{P}_{2} \mathrm{~K}_{2}$ treatments, respectively. According to the paired t-tests, no significant differences were found between the observed and simulated yields. The annual yields of the control and $\mathrm{N}_{2} \mathrm{P}_{2} \mathrm{~K}_{2}$ treatments for the 1961-2010 period are presented in Fig 7., while the cumulative yields are presented in Fig. 8. The model underestimated the observed yields especially for the high-yield years. In the low-yield years this tendency was reversed especially for the fertilized treatments.
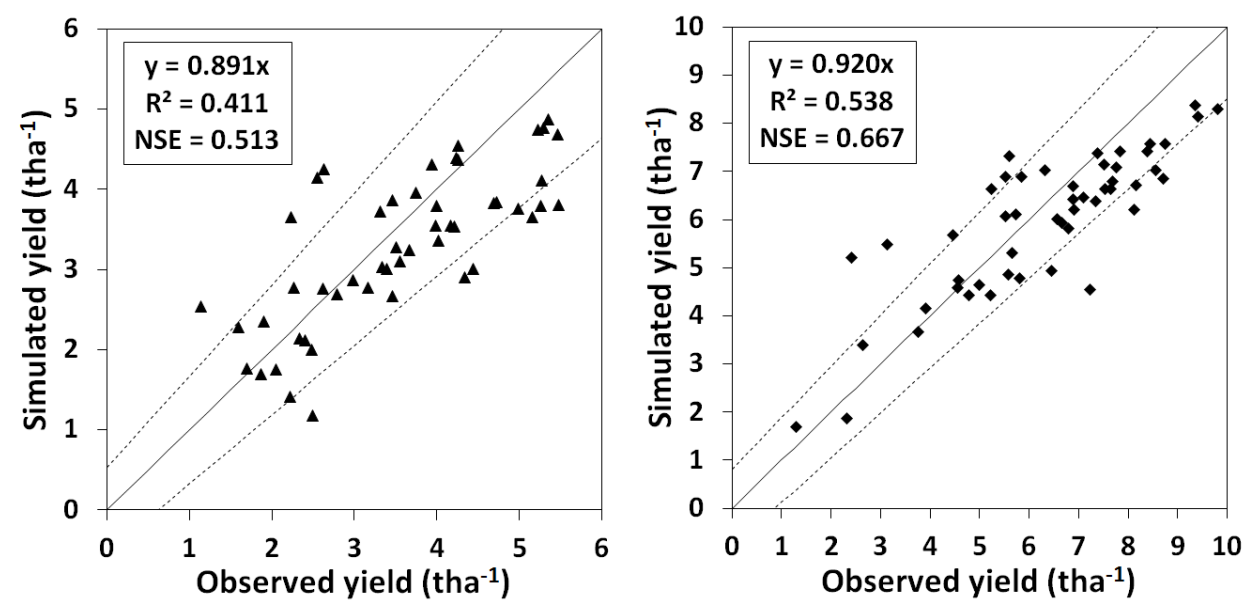

Figure 7. Simulated vs observed yields for the control (left) and the $\mathrm{N}_{2} \mathrm{P}_{2} \mathrm{~K}_{2}$ treatments (right) for the 1961-2010 period. Dotted lines indicate the 20\% relative error threshold.

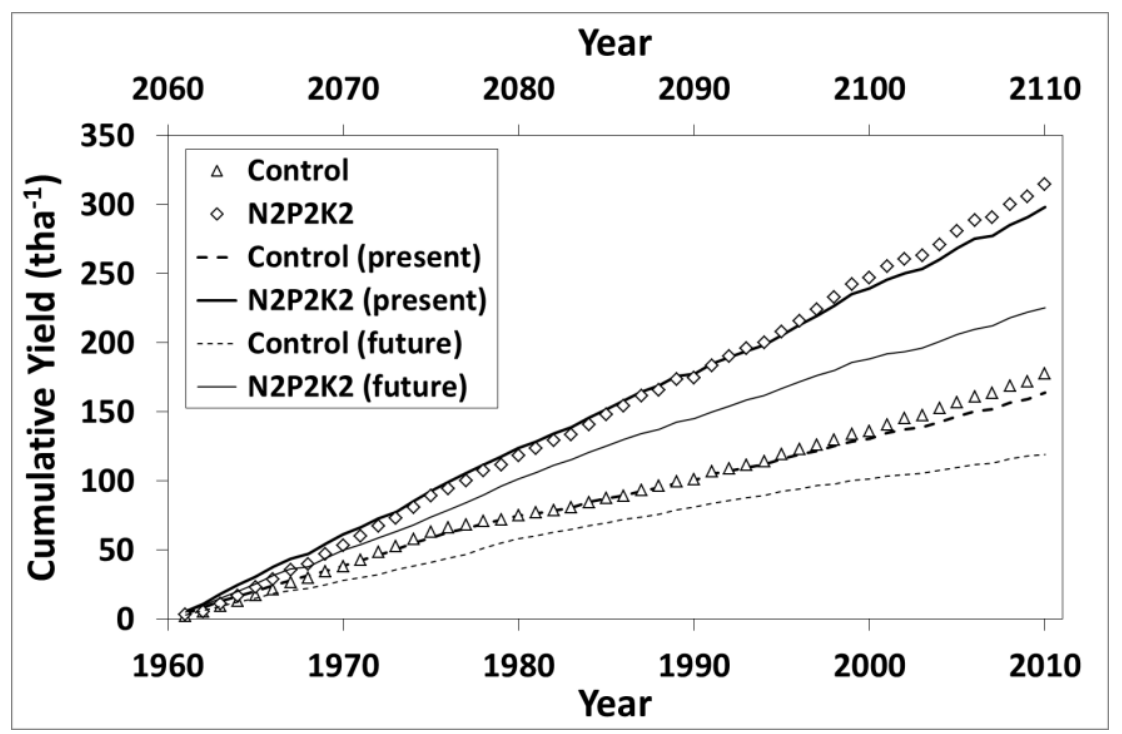

Figure 8. Observed (dots) and simulated (lines) cumulative yields for the control and the $\mathrm{N}_{2} \mathrm{P}_{2} \mathrm{~K}_{2}$ treatments, for the 1961-2010 (heavy lines) and the 2061-2110 (thin lines) periods. 
The model underestimated the inter-annual variability of the yield for all of the treatments. The standard deviation of the observed and the simulated yields was 1.19 and 0.62, 1.84 and 0.97, 1.98 and 1.08 tha $^{-1}$ for the control, $\mathrm{N}_{1} \mathrm{P}_{1} \mathrm{~K}_{1}$ and $\mathrm{N}_{2} \mathrm{P}_{2} \mathrm{~K}_{2}$ treatments, respectively. This result emphasizes the fact that the model is still not capable of estimating the effects of yield-limiting and yield-reducing factors adequately. Most likely, the parameters used to simulate heat and water stress induced senescence (Eq. 1.) do not completely explain variations of leaf decay rate. $4 \mathrm{M}$ is not the only model with this type of weakness as recent studies have revealed that the response of plants to a combination of two different abiotic stresses is unique and cannot be directly extrapolated from the response of plants to each of the different stresses applied individually (Mittler, 2006). 4M was able to predict the long-term trends and averages of biomass productions adequately (Fig. 8.) for the investigated treatments. However, there were two periods when the model considerably and systematically over- (19611963) or underestimated (1995-2010) the observed yields. The first deficiency could be explained by the fact that these were the 3rd to 5th years of the long-term experiment when the effects of the treatments had not been consolidated yet and the spatial variability of the soil might have significantly distorted the observed data. This result supports the practice that data of the first 4-6 years of long-term experiments are usually not used when observations are evaluated. The systematic underestimation of the model for the last decade of the 1961-2010 period could be an indirect evidence for climate change or (at least) for the effect of the elevated air $\mathrm{CO}_{2}$ concentration. The postulated $350 \mathrm{ppm}$ atmospheric $\mathrm{CO}_{2}$ concentration was most likely not valid for the end of the investigated period (CO2now, 2015). The capability of long-term experiments to scientifically demonstrate that climate change is actually happening has already been presented (Henkin et al., 2010). Another possible origin of the underestimation is the increased efficiency of the modern cultivars. Though their specific radiation use efficiency is not higher but their architecture (leaf angle) and stress tolerance is clearly better than those of the older hybrids. The Norma hybrid that had been bred in the Agricultural Institute, has been sown every year in the experiment since 1991. This variety has specifically high average harvest index and drought tolerance, neither of which has been simulated sufficiently by the model.

The root mean squared error (RMSE), the mean absolute error (MAE) the mean relative error (MRE) and the Nash-Sutcliffe model efficiency coefficient (NSE) of the yield simulations for the parcels of the 294 farms in the 2001-2010 period were the following: RMSE $=1.28 \mathrm{tha}^{-1} ; \mathrm{MAE}=1.03 \mathrm{tha}^{-1} ; \mathrm{MRE}=15.7 \%$ NSE $=0.641$. These error indicators represent a quite good model performance. The observed vs. simulated yield data points are scattered symmetrically along the 1:1 lines on Fig. 9. and Fig. 10. except for sandy soils and low yielding years, as it can be especially seen on Fig. 10, in 2007 which was an extremely droughty year.

The results of the model validation confirm the fact that the $4 \mathrm{M}$ model still has the weakness of simulating the yield formation in extreme environmental conditions: e.g. droughts and/or soils with poor water holding capacity. On the other hand, in average, the model is capable to simulate the biomass formation with acceptable accuracy.

According to the simulation projections prospective yields will considerably decrease due to climate change (Fig. 8.). One hundred years from now average yields will be some $25 \%$ lower than the present yields. Even though higher $\mathrm{CO}_{2}$ concentration in the atmosphere results in an increased plant stomatal resistance and in a better water use efficiency (Anda and Kocsis, 2008), this effect cannot counterbalance the summer water 
shortage. The coefficient of variation (cv) of the simulated yields was considerably higher for the future climate scenario (control: $32 \%, \mathrm{~N}_{2} \mathrm{P}_{2} \mathrm{~K}_{2}: 25 \%$ ) than for the present (control: $19 \%, \mathrm{~N}_{2} \mathrm{P}_{2} \mathrm{~K}_{2}: 18 \%$ ). These figures predict a considerable decrease of yield safety. These findings are in line with the results of earlier studies that also predict the decrease of yields (Bacsi et al., 1991; Harnos et al., 2002) owing to the increase of water limitation in crop production. According to Olesen et al. (2011) the increased risk of hail, pest and weed damages will further decrease the agricultural productivity in the Carpathian basin.
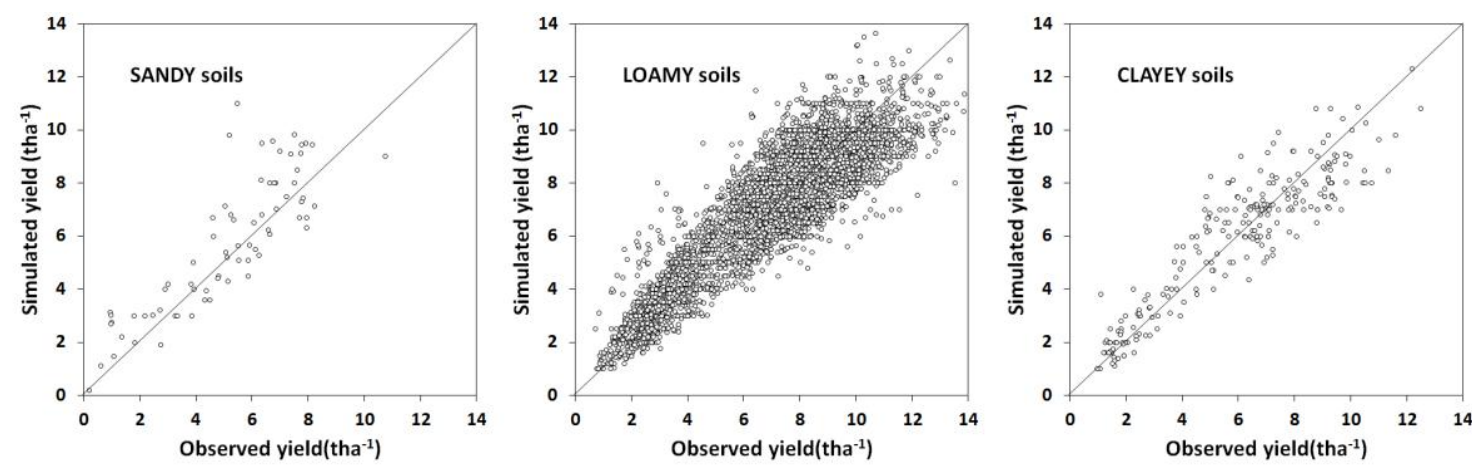

Figure 9. Observed and simulated yields of the representatively selected 294 Hungarian farms between 2001 and 2010 as a function of the soil type of the parcels.
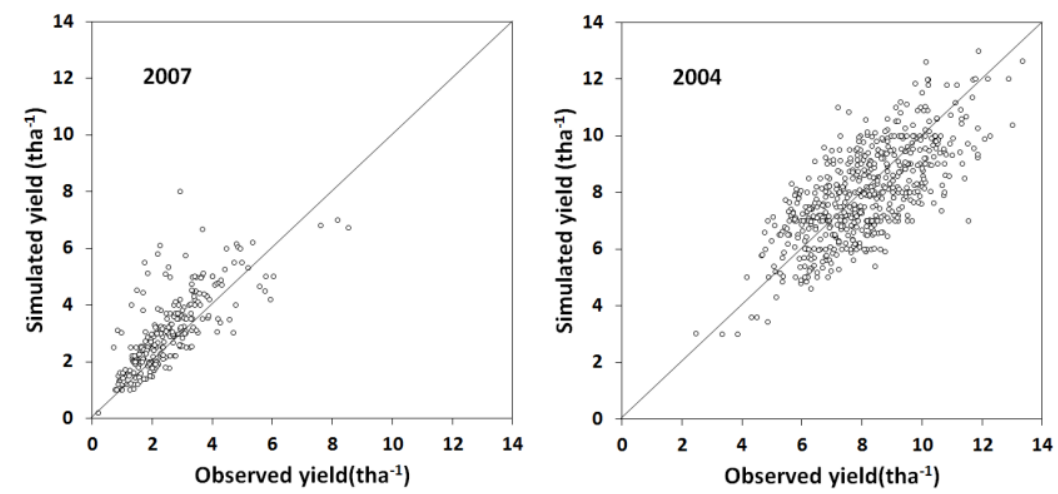

Figure 10. Observed and simulated yields of the representatively selected 294 Hungarian farms in 2007 (very droughty year) and 2004 (above average year).

According to the observations, the 50-year average yield of the $\mathrm{N}_{2} \mathrm{P}_{2} \mathrm{~K}_{2}$ treatment is only 0.5 tha $^{-1}$ higher than that of the $\mathrm{N}_{1} \mathrm{P}_{1} \mathrm{~K}_{1}$ treatment. To achieve this yield surplus, $66 / 38 / 75 \mathrm{~N} / \mathrm{P}_{2} \mathrm{O}_{5} / \mathrm{K}_{2} \mathrm{O} \mathrm{kgha}^{-1}$ more active ingredient mineral fertilizer was applied to the $\mathrm{N}_{2} \mathrm{P}_{2} \mathrm{~K}_{2}$ treatment. Based on the average fertilizer and crop prices for the 1961-2010 period, the average income for the less intensively fertilized treatment would have been $1300 € \mathrm{~h}^{-1} \mathrm{y}^{-1}$ more than that of the more intensively fertilized treatment. For the climatic zone and for the soil type of the long-term experiment, which gives a considerable portion of the arable land in Hungary, it is not profitable to intensively fertilize the maize crop. This piece of information serves as an excellent example of how long-term experiments may support decision makers and even policy makers. 


\section{Conclusions}

The efficiency of the 4M crop model in simulating the effects of different fertilizer levels was presented in this study. Calculated biomass formation data were compared to observed data which were collected in a long-term field experiment. The model successfully simulated the differences between the years, as well as the effects of the different fertilization levels. According to the results, using the more detailed observation data of three years, the model could be successfully calibrated to predict the long-term trends and averages of biomass productions adequately. On the other hand, the model underestimated the inter-annual variability of the yield which is an indicator of a more fundamental problem of crop modeling. At their present stage, crop models are unable to handle the effects of environmental (biotic and abiotic) stress factors adequately. Given that the current projections predict the increase of frequency of some extreme weather phenomena under climate change, this may lead to a severe underestimation of yield losses and yield variability when crop models are combined with climate change scenarios. Consequently, even though the $4 \mathrm{M}$ projection predicts considerable decrease of maize yields, as well as yield safety, the future reality could be considerably worse. The observations suggest two possible ways of model improvement. The model should have the ability 1) to change the assimilate partition and 2) to change the light use efficiency in nitrogen limited situations. More generally, model developers should aim at improving the capacity of crop models to project the impact of environmental (biotic and abiotic) stress factors especially focusing on their interdependent actions.

Concerning the projected maize yield losses, which may exceed 1,000,000 ton per year for the Carpathian basin according to the predictions, Hungarian farmers and agricultural enterprises should consider investing in irrigation to mitigate the harmful effects of severe summer hot and dry periods. The projected increase in food demand, as well as the need for increasing yield safety definitely substantiate investments in irrigation in Hungary similarly to the Mediterranean countries whose present climate is similar to the future climate of the Carpathian basin (Horváth, 2008). One possible way of accommodating the climatic changes is to increase the ratio of crops sown in the autumn in the crop rotation since these crops are less affected by the summer droughts. Another alternative for Hungarian agriculture is to start experimenting with alternative crops, such as energy crops (robinia (Robinia pseudoacacia), poplar (Populus), etc.) or crops native to or successfully produced in Mediterranean areas (fenugreek (Trigonella foenum-graecum L.), lady's thistle (Silybum marianum (L.) Gaernt.) or cotton (Gossypium), etc.). Well calibrated crop simulation models could support these testing efforts by carrying out virtual experiments.

Acknowledgment. The authors gratefully acknowledge the financial support of the OTKA-104816 and OTKA-105789 research funds. The first author's research was supported by the European Union and the State of Hungary, co-financed by the European Social Fund in the framework of TÁMOP 4.2.4. A/2-111-2012-0001 'National Excellence Program'. 


\section{REFERENCES}

[1] Anda, A., Kocsis, T. (2008): Impact of atmospheric $\mathrm{CO}_{2}$ enrichment on some elements of microclimate and physiology of locally grown maize. - Applied Ecology and Environmental Research 6: 85-94.

[2] Audsley, E., Pearn, K. R., Simota, C., Cojocaru, G., Koutsidou, E., Rounsevell, M. D. A., Alexandrov, V. (2006): What can scenario modelling tell us about future European scale agricultural land use, and what not? - Environmental Science \& Policy 9(2): 148-162.

[3] Bacsi, Zs., Thornton, P.K., Dent, J.B. (1991): Impacts of future climate change on Hungarian crop production: An application of crop growth simulation models. Agricultural Systems 37: 435-450.

[4] CECILIA (2009): Deliverable 3.3: Assessment of the applicability of RCM and SDS models in the impact target areas by their validation according to relevant criteria; ranking of the models if possible pp. 34-40. http://www.ceciliaeu.org/restricted/deliverables.php. (Accessed: 08 Oct 2013)

[5] CO2now (2013): http://co2now.org/ (Accessed: 07 May 2015)

[6] Déqué, M., Marquet, P., Jones, R.G. (1998): Simulation of climate change over Europe using a global variable resolution general circulation model. - Climate Dynamics 14: 173-189.

[7] Egner, H., Riehm, H., Domingo, W. (1960): Unterschuchungenüber die chemische Bodenanalyseals Grundlage für die Beurteilung des Nährstoffzustandes der Böden II. Chemische Extraktions methoden zur Phosphor- und Kaliumbestimmung. - Kungliga Lantbrukshögskolans Annale 26: 199-215. (In German)

[8] Eitzinger, J., Trnka, M., Hösch, J., Žalud, Z., Dubrovský, M. (2004): Comparison of CERES, WOFOST and SWAP models in simulating soil water content during growing season under different soil conditions. - Ecological Modelling 171(3): 223-246.

[9] Fezzi, C., Bateman, I., Askew, T., Munday, P., Pascual, U., Sen, A., Harwood, A. (2014): Valuing provisioning ecosystem services in agriculture: The impact of climate change on food production in the United Kingdom. - Environmental and Resource Economics 57(2): 197-214.

[10] Fisher, R.A. (1921): Studies in crop variation. I. An examination of the yield of dressed grain from Broadbalk. - Journal of Agricultural Science 11: 107-135.

[11] Fodor, N., Csathó, P., Árendás, T., Németh, T. (2011): New environment-friendly and cost-saving fertiliser recommendation system for supporting sustainable agriculture in Hungary and beyond. - Journal of Central European Agriculture 12(1): 53-69.

[12] Fodor, N., Máthéné-G.G., Pokovai, K., Kovács, G.J. (2002): 4M - software package for modelling cropping systems. - European Journal of Agronomy 18: 389-393.

[13] Fodor, N., Pásztor, L. (2010): The agro-ecological potential of Hungary and its prospective development due to climate change. - Applied Ecology and Environmental Research 8: 177-190.

[14] Fodor, N, Pásztor, L, Németh, T. (2014): Coupling the 4M cropmodel with national geodatabases for assessing the effects of climate change on agro-ecological characteristics of Hungary. - International Journal of Digital Earth 7(5): 391-410.

[15] Gijsman, A.J., Hoogenboom, G., Parton, W.J., Kerridge, P.C. (2002): Modifying DSSAT for low-input agricultural systems, using a soil organic matter residue module from CENTURY. - Agronomy Journal 94(3): 462-474.

[16] Harnos, N., Bencze, S., Janda, T., Juhasz, A., Veisz, O. (2002): Interactions between elevated $\mathrm{CO}_{2}$ and water stress in two winter wheat cultivars differing in drought resistance. - Cereal Research Communications 30: 359-366.

[17] Henkin, Z., Perevolotsky, A., Sternberg, M. (2010): Vulnerability of Mediterranean grasslands to climate change: What can we learn from a long-term experiment? - In: Porqueddu, C., Ríos, S. (eds) The Contributions Of Grasslands To The Conservation Of 
Mediterranean Biodiversity. Zaragoza: CIHEAM/CIBIO/ FAO/SEEP, 2010. p. 167-174

(Options Méditerranéennes: Série A. Séminaires Méditerranéens; n. 92).

[18] Hodges, T. (1990): Predicting Crop Phenology. - CRC Press, Boca Raton, London, New York.

[19] Horváth, L. (2008): Use of spatial analogy method to analyze to possible land use change in Hungary. - CLIMA-21 Brochures 55: 23-27.

[20] IPCC (2007): Intergovernmental Panel on Climate Change (IPCC) WG1 Fourth Assessment Report, Climate Change: The Physical Science Basis, Summary For Policymakers.

[21] IPCC (2014): http://www.ipcc-data.org/observ/ddc_co2.html. (Accessed: 20 Feb 2014)

[22] Jamieson, P. D., Porter, J. R., Goudriaan, J., Ritchie, J. T., van Keulen, H., Stol, W. (1998): A comparison of the models AFRCWHEAT2, CERES-Wheat, Sirius, SUCROS2 and SWHEAT with measurements from wheat grown under drought. - Field Crops Research 55(1-2): 23-44.

[23] Jenkinson, D.S. (1990): The turnover of organic carbon and nitrogen in soil. Philosophical Transactions of the Royal Society B 329, 361-368.

[24] Kismányoky, T., Jolánkai, M. (2009): Long-term fertilization experiments in Hungary. In Debreczeni, Bné., Németh, T. (eds). Scientific Results Of The Hungarian Long-term Fertilization Experiments (1967-2001). - Akadémiai Publisher, Budapest, 25-33.

[25] Klein, T., Calanca, P., Holzkämper, A., Lehmann, N., Roesch, A., Fuhrer, J. (2012): Using farm accountancy data to calibrate a crop model for climate impact studies. Agricultural Systems 111: 23-33.

[26] Knox, J.W., Hurford, A., Hargreaves, L., Wall, E. (2012): Climate Change Risk Assessment for the Agriculture Sector. DEFRA report.

[27] Korsaeth, A. (2012): N, P, and K budgets and changes in selected topsoil nutrients over 10 years in a Long-Term Experiment with conventional and organic crop rotations. Applied and Environmental Soil Science, Article ID 539582, 17 p, 2012. doi:10.1155/2012/539582.

[28] Máthé-Gáspár, G., Fodor, N. (2012): Modeling the phosphorus balance of different soils using the 4M crop model. - Plant, Soil and Environment 58(9): 391-398.

[29] Mittler, R. (2006): Abiotic stress, the field environment and stress combination. - Trends Plant Science 11(1): 15-19.

[30] Nakicenovic, N., Swart, R. (eds) (2000): Special report on emission scenarios. Cambridge University Press, Cambridge.

[31] Nash, J.E., Sutcliffe, J.V. (1970): River flow forecasting through conceptual models part I - A discussion of principles. - Journal of Hydrology 10(3): 282-290.

[32] Olesen, J.E., Bindi, M. (2002). Consequences of climate change for European agricultural productivity, land use and policy. - European Journal of Agronomy 16(4): 239-262.

[33] Olesen, J.E., Trnka, M., Kersebaum, K.C., Skjelvag, A.O., Seguin, B., Peltonen-Sainio, P.,Rossi, F., Kozyra, J., Micale, F. (2011): Impacts and adaptation of European crop production systems to climate change. - European Journal of Agronomy 34, 96-112.

[34] Pásztor, L., Szabó, J., Bakacsi, Z., Laborczi, A., Dobos, E., Illés, G., Szatmári, G. (2014): Elaboration of novel, countrywide maps for the statisfaction of recent demands on spatial, soil related information in Hungary. - In: Arrouays, D., McKenzie, N. et al. (eds.) Global Soil Map: Basis Of The Global Spatial Soil Information System. Taylor \& Francis Group, London, 207-212.

[35] Peltonen-Sainio, P., Jauhiainen, L., Hakala, K., Ojanen, H. (2009): Climate change and prolongation of growing season: Changes in regional potential for field crop production in Finland. - Agricultural and Food Science 18: 171-190.

[36] Ramirez-Cabral, N.Y.Z., Kumar, L., Taylor, S. (2016): Crop niche modeling projects major shifts in common bean growing areas. - Agricultural and Forest Meteorology 218219: 102-113. 
[37] Rasmussen, P.E., Goulding, K.W.T., Brown, J.R., Grace, P.R., Janzen, H.H., Körschens, M. (1998): Long-Term Agroecosystem Experiments: Assessing Agricultural Sustainability and Global Change. - Science 282: 893-896.

[38] Ray, D.K., Mueller, N.D., West, P.C., Foley, J.A. (2013): Yield trends are in sufficient to double global crop production by 2050. - PLOS ONE 8: e66428. doi:10.1371/journal.pone.0066428.

[39] Ritchie, J.T., Singh, U., Godwin, D.C., Bowen, W.T. (1998): Cereal growth, development and yield. - In: Tsuji, G.Y., Hoogenboom, G., Thornton, P.K. (eds): Understanding Options For Agricultural Production. Kluwer Academic Publishers, Dordrecht. 79-98.

[40] Rosenzweig, C. Parry, M.L. (1994): Potential impacts of climate change on world food supply. - Nature 367: 133-138.

[41] Sándor, R., Fodor, N. (2012): Simulation of soil temperature dynamics with models using different concepts. - The Scientific World Journal. Article ID 590287, 8 pages. DOI:10.1100/2012/590287.

[42] Schepers, J.S., Francis, D.D., Virgil, M., Below, R.E. (1992): Comparison of corn leaf nitrogen concentration and chlorophyll meter readings. - Communication in Soil Science and Plant Analysis 23: 2173-2187.

[43] Semenov, M.A., Shewry, P.R., (2011): Modelling predictsthat heat stress, not drought, will increase vulnerability of wheat in Europe. - Natural Sciences Rep. 1. http://dx.doi.org/10., 1038/srep00066.

[44] Soetaert, K., Petzoldt, T. (2010): Inverse modelling, sensitivity and Monte Carlo analysis in R Using Package FME. - Journal of Statistical Software 33(3): 1-28.

[45] Southwood, T.R.E. (1994): The importance of long-term experimentation. - In: Leigh, R.A., Johnston, A.E. (eds) Long-Term Experiments In Agricultural And Ecological Sciences. CAB International, Wallingford, 3-8.

[46] Spinoni, J. and the CARPATCLIM project team (39 authors) (2014): Climate of the Carpathian Region in 1961-2010: Climatologists and Trends of Ten Variables. International Journal of Climatology. Article first published online: 12 June 2014. 2014. DOI: $10.1002 /$ joc. 4059 .

[47] Stockle, C.O., Nelson, R.L. (1996): Cropsyst User's manual (Version 2.0). Biological Systems Engineering Dept., Washington State University, Pullman, Washington.

[48] Supit, I., van Diepen, C.A., de Wit, A.J.W., Kabat, P., Baruth, B., Ludwig, F., (2010): Recent changes in the climatic yield potential of various crops in Europe. - Agricultural Systems 103: 683-694.

[49] Szentimrey, T., Bihari, Z., Lakatos, M., Szalai S. (2011): Mathematical, methodological questions concerning the spatial interpolation of climate elements. - Időjárás 115, 1-11.

[50] Tyurin, I.V. (1937): Organic matter of soils. - Szelhozgiz. Moscow (in Russian).

[51] Wang, Y., Bellus, M., Wittmann, C., Steinheimer, M., Weidle, F., Kann, A., IvatekSahdan, S., Tian, W., Ma, X., Bazile, E. (2011): The Central European limited area ensemble forecasting system: ALADIN-LAEF. - Quarterly Journal of the Royal Meteorological Society 137: 483-502.

\section{ELECTRONIC APPENDIX}

Appendix 1. Long-term Field Experiment, Martonvásár, Hungary

Appendix 2. N1P1K1 treatment, 22. 06. 2006

Appendix 3. N2P2K2 treatment, 22. 06. 2006

Appendix 4. Control and N2P2K2, 25. 06. 2006

Appendix 5. N2P2K2 stages, 2006

Appendix 6. Control treatment, 2006 